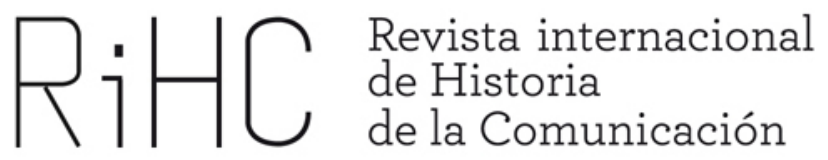

\title{
LA LOCUCIÓN RADIOFÓNICA EN CANARIAS DURANTE EL FRANQUISMO
}

DOI: http://dx.doi.org/10.12795/RiHC.2013.i01.08

Julio Yanes

Universidad de la Laguna

jayanes@ull.es

Resumen: En el presente artículo abordamos la implantación y el desarrollo de la locución radiofónica franquista, como un capítulo más del afán centralizador y uniformador del estado español por el régimen, en el contexto específico de las Islas Canarias. Para subsanar las escasísimas huellas documentales legadas por este componente, el más volátil, del mecanismo comunicativo articulado a través de las ondas hertzianas, hemos recurrido a fuentes orales y a archivos privados y personales. Ello nos ha permitido rescatar un cúmulo de datos que, sin generar conocimiento, estaban condenados a desaparecer con la defunción de las personas correspondientes. Sobre tales bases, hemos podido recrear detalles muy jugosos sobre la dinámica de los cursos de locución de la época y la reacción, a corto y medio plazo, de la sociedad insular ante la imposición de una norma ajena a los usos cotidianos de ésta.

Palabras clave: franquismo, locución radiofónica, centralización del estado español, habla canaria, Islas Canarias

Abstract: On this article we tackle the introduction and development of radio broadcasting during the Franco period as another chapter in the monopolizing and uniforming zeal displayed by the Spanish state in order to establish the rule, on the specific context of the Canary Islands. Owing to the truly limited documentary 
information about this inconstant subject, an articulated communicative mechanism through the hertzians waves, we have focused on oral sources and personal and private archives. This approach has allowed us to save a lot of references that, even without supplying knowledge, were condemned to disappear with the death of the people involved. Upon this base, we had been able to recreate very succulents details about the process of broadcasting courses on that time, and the reaction, on a short and middle time, of the insular society with regard to the imposition of a foreign pattern, so different to daily customs.

Keywords: Franco period, radio-broadcasting, Spanish state centralization, speech of the Canary Islands, Canary Islands. 


\section{Planteamiento}

Como es de sobra conocido, el organigrama político-administrativo de la dictadura franquista se caracterizó, en clara antítesis con el actual Estado de las Autonomías, por su fuerte centralización en Madrid, en coherencia con la visión monolítica que de España tenían los ideólogos del régimen. En un país tan diverso y heterogéneo como el que nos ocupa, el elemento articulador de tal andamiaje fue la campaña propagandística mediática con la que, a través de una férrea censura y un sistema de consignas, se intentó homogeneizar a toda la población. El objetivo era superponer sobre la pluralidad cultural del territorio estatal un sistema de valores totalitario que, aunando a todos los ciudadanos detrás de unas aspiraciones "patrióticas» comunes, entroncara con los patrones culturales que se consideraban definitorios de la «nación española». Junto a la prensa, la radio jugó un papel de primer orden antes de la llegada de la televisión, tanto con la emisión de los contenidos oportunos como con el hecho de hacerlo en el más puro castellano, la dicción genuinamente "española», en detrimento de las diferentes lenguas y hablas que se practican a lo largo y ancho de todo el Estado. Por razones obvias, donde más dificultosa resultó tal imposición fue en las demarcaciones territoriales más alejadas del "centro», caso de las Islas Canarias, cuyos hablantes se distinguen por el uso de unos registros fónicos, gramaticales y léxicos que están emparentados con los de la otra orilla del Atlántico por la tradicional emigración a Cuba y Venezuela (Díaz Alayón, C., Morera, M. \& Ortega, G, 2003).

En los renglones que siguen, nos hemos propuesto analizar en este enclave tan singular y periférico del estado español, el archipiélago canario, la implantación y la evolución posterior de la ortodoxia franquista en la locución radiofónica. En concreto, los objetivos de la investigación son dos: en primer lugar, conocer el procedimiento a través del cual se consiguieron las voces radiofónicas de la España homogénea soñada por el régimen en un lugar de habla tan heterodoxa y, en segundo lugar, calibrar la reacción, a corto y medio plazo, de la sociedad insular ante tal injerto cultural. Como colofón, desde el propio conocimiento histórico que nos ha brindado el trabajo, hemos traído la reflexión sobre el tema abordado hasta la actualidad y, luego, apuntalado las conclusiones con una valoración del procedimiento seguido en la investigación. 


\section{Estado de la cuestión, fuentes y metodología}

Conocidas son las dificultades epistemológicas que en la actualidad entraña la construcción de todo conocimiento histórico referido globalmente a España, tanto por la pluralidad cultural del objeto de estudio como por los desafíos que, desde finales de la centuria anterior, han traído las corrientes posmodernas a la investigación histórica. En el caso específico de la radio, los problemas se agigantan porque, al margen de tales escollos, la empresa conlleva el análisis de las piezas que han articulado un mecanismo comunicativo tan etéreo como el de las ondas hertzianas, desde el sujeto emisor al receptor, pasando por el canal y el código a través de los cuales el mensaje llega a los destinatarios y, luego, se deja sentir en toda la sociedad. Incluso en los años del centralismo franquista, cuando la dinámica de la vida española estaba uniformizada por una férrea dictadura, el quehacer del sector tampoco era homogéneo en todo el Estado por los distintos niveles de desarrollo existentes entre las diversas demarcaciones territoriales. Por todo ello, el estudio específico de la radio en los enclaves periféricos y marginales, donde los logros de las zonas punteras llegaron, si es que lo hicieron, más tardía y modestamente por las mayores limitaciones contextuales, tiene un indudable interés científico para, poco a poco, ir detectando las semejanzas y las diferencias que, tanto sincrónica como diacrónicamente, nos permitan conocer el desenvolvimiento del medio a lo largo y ancho de todo el territorio estatal. Más aún cuando estos trabajos a menudo sacan a la luz realidades ocultas que nos obligan a matizar, cuando no a replantear, las generalizaciones extrapoladas indiscriminadamente al conjunto del Estado a partir de las investigaciones ceñidas a los polos más desarrollados.

La historia de la radiodifusión española en el franquismo ha sido abordada tanto en espacios territoriales o cronológicos muy concretos, caso de las conocidas obras de Rosa Franquet y de Carmelo Garitaonaindía, como globalmente, de lo que buenos exponentes son los trabajos de Armand Balsebre y Juan Faus Belau. Las aportaciones de éstos y los restantes autores, cuya enumeración aquí consideramos ociosa, no se agota con el conocimiento explícito que ofrecen sus textos porque, implícitamente, todos han dejado en evidencia los múltiples aspectos que, desde el punto de vista del mecanismo comunicativo y del papel del medio en los contextos marginales, reclaman la atención específica de los investigadores. Entre tales vertientes, particular dificultad presenta la locución por su volatilidad y las escasísimas, por no decir nulas, huellas documentales que nos ha legado su desenvolvimiento diario en los archivos, en contraposición al contenido de los mensajes que, incluso, eran reproducidos a menudo por la prensa en los años iniciales y centrales de la dictadura. Precisamente, éste ha sido el reto que nos hemos atrevido a asumir en el presente artículo, con el doble acicate de hacerlo en un espacio tan periférico y olvidado en las síntesis históricas de la 
radiodifusión española como las Islas Canarias, merced a un repertorio de fuentes orales e impresas inéditas ${ }^{1}$ que, al pertenecer al ámbito privado, estaban condenadas a su desaparición. Para apuntalar tan valiosa información, hemos recurrido a las fuentes hemerográficas y bibliográficas citadas en sus lugares oportunos, las cuales nos han permitido depurar y contextualizar los datos recabados antes de proceder a la narración de los hechos.

El trabajo, por lo demás, forma parte de una línea de investigación abierta en el Departamento de Ciencias de la Información de la Universidad de La Laguna, en la que, con el estudio minucioso de las partes que componen el todo, se pretende construir, "desde abajo hacia arriba», una historia de la radio canaria que dé juego a toda la dinámica del medio, desde el emisor al receptor, pasando por el canal, el código y el mensaje, en todo el territorio insular. A tal fin, estamos afrontando una serie de problemas cuyo interés, como es el caso de la imposición lingüística que nos ocupa, rebasa ampliamente el contexto isleño e, incluso, el estatal, al referirse a hechos que históricamente han estado presentes en todas las culturas. En consecuencia, la razón de ser de nuestra metodología es, tal y como sintetizara Emmanuel Le Roy Ladurie cuando se ocupó de la aldea francesa Montaillou, «estudiar el océano en una gota de agua» (Burke, 1999: 84), a sabiendas de que el examen de los temas globales en microespacios diferenciados y singulares como el canario tienen interés para el estado de la cuestión a escala internacional. El objetivo final es ofrecer un conocimiento científico muy pegado a las vivencias de las personas e insertable, con las aportaciones homólogas que surjan en el resto del Estado, en una historia de la radio española cuyo contenido refleje, tanto sectorial como territorialmente, la exhaustividad implícita al título enunciado.

\footnotetext{
${ }^{1}$ Entre el centenar de locutores, técnicos y colaboradores entrevistados de las emisoras de la época, varios de los cuales ya han fallecido, especial mención por suministrarnos los datos más valiosos merecen: Juan Antonio Rolo Hernández (13/04/1939) y Eloy Díaz de la Barreda (29/08/1927) de Radio Club Tenerife; José Antonio Pardellas Casas (27/01/1938), César Fernández-Trujillo de Armas (24/06/1937), María de la Cruz Domínguez García (08/12/1935), Antonio Abdo Pérez (19/02/1937), Juan Petronilo Hernández García (31/05/1946) y Juan Jesús Pérez Pérez (12/01/1952) de Radio Juventud de Canarias; José Siverio Pérez (29/11/1928), Isabel Dorta Hernández (08/07/1919), Arsenio León Cabrera (03/07/1939), Jorge González Pérez (09/02/1942), Salvador García Llanos (20/05/1953) y Juan Cruz Ruiz (27/09/1949) de La Voz del Valle de La Orotava; Nieves Pilar Rey Brito (15/01/1944) y Teresa Alfonso Segado (21/04/1945) de La Voz de la Isla de La Palma; y José Ramos González (20/02/1931), Javier Apraiz de Elorza (07/12/1936), Ramón Negrín Fragoso (15/12/1941) y María Isabel Medina Brito (24/06/1943) de Radio Popular de Güímar.
} 


\section{Las ondas hertzianas isleñas durante el franquismo}

Los primeros pasos de la radiodifusión en Canarias datan de mediados de los años veinte del siglo pasado, cuando dos radiotécnicos alemanes establecidos en las islas, Juan Meinke en Santa Cruz y Arturo Gebauer en Las Palmas, montaron las primeras emisoras en onda corta a partir de sus equipos de radioaficionados. Tras unos años de actividad alegal en los que, poco a poco, las emisiones fueron mejorando con el instrumental donado por las casas comerciales del ramo y las cuotas aportadas por los radioescuchas a través de sendos clubes, las juntas directivas de ambas asociaciones se acogieron a la legislación promulgada el 8 de diciembre de 1932 sobre emisoras de baja potencia para introducir, desde mediados de 1934, la señal de onda media. A partir de entonces, las ya legalizadas Radio Club Tenerife EAJ-43 y Radio Las Palmas EAJ-50 desarrollaron su actividad, al igual que el medio centenar restante de estaciones locales que aparecieron por entonces en España, en un área de cobertura tan reducida que, en el caso que nos ocupa, se circunscribía a los hinterland de las capitales insulares, quedando amplias zonas de sombra en el archipiélago. El panorama cambió radicalmente durante la guerra civil y la II Guerra Mundial, cuando los sublevados contra la República dotaron a la emisora tinerfeña de varios canales de salida suplementarios de onda corta para hacer propaganda de la causa fascista en todo el mundo. Tras el cese de las hostilidades, Radio Club Tenerife recuperó su humilde papel de estación local de baja potencia para, en los durísimos años de la autarquía y las cartillas de racionamiento, seguir activa, no sin grandes dificultades, junto con su homóloga grancanaria.

Sería a mediados de la década de los cincuenta cuando, una vez había pasado lo peor de la posguerra, el régimen montó las primeras emisoras «institucionales» en las islas, Radio Atlántico de la Cadena de Emisoras Sindicales (CES) en Las Palmas y Radio Juventud de Canarias de la Cadena Azul de Radiodifusión (CAR) en Santa Cruz. Luego, cuando a inicios de los años sesenta el país entraba en el desarrollismo que trajo el boom turístico, el panorama se diversificó aún más con la simultánea puesta en marcha, en localidades ajenas a las dos capitales provinciales, de La Voz del Valle de La Orotava, La Voz de la Isla de La Palma y Radio Popular de Güímar, las dos primeras de la CES y la última de la embrionaria Cadena de las Ondas Populares Españolas (COPE). A todas ellas se añadieron más tarde Radio Ecca en Las Palmas y, con el cambio de década, Radio Popular de Las Palmas y Radio Popular de Tenerife en La Laguna, con el subsiguiente cierre de la estación previa de la COPE en Güímar. En esta década también estuvieron activas, aunque con un papel muy marginal, dos estaciones artesanales habilitadas por la Iglesia en la basílica de Candelaria y la catedral de Las Palmas, así como otra de frecuencia modulada, La Voz de Canarias de la CES, cuyo corto ciclo vital entre 1963 y 1965 se debió a los escasísimos receptores que había en 
el archipiélago para captar tal tipo de señal. Para completar el sistema radiofónico insular en el franquismo, nos resta el canal comunicativo regional que, a mediados de 1964, tejió el Centro emisor del Atlántico de Radio Nacional de España, el primero de la historia que, junto con la recién inaugurada Televisión Española en Canarias, puso la actualidad y la problemática de todas las islas en una plataforma común y compartida por todos los isleños.

En definitiva, se trataba de un subsistema radiofónico tan singular dentro del sistema, o ecosistema, comunicativo de la España franquista, como singular era, y sigue siendo, el contexto isleño dentro del estatal al calor de su emplazamiento al noroeste de la costa africana, su alejamiento a un millar y medio de kilómetros de la península, su fragmentación en islas muy heterogéneas, su dependencia del exterior, su tradicional vinculación económica con el área de la libra esterlina y, para no hacer interminable la relación de los rasgos diferenciales, sus lazos humanos con Latinoamérica. Fue sobre tan singular contexto, en el que la singularidad comprende todas las vertientes culturales incluyendo la lingüística, donde la dictadura franquista se empeñó en implantar la locución radiofónica en un habla tan diferente a la local como el castellano en su expresión más ortodoxa.

\section{La estación-escuela de la Cadena Azul de Radiodifusión (CAR)}

No sería hasta la segunda mitad de la década de los cincuenta cuando, tras la llegada de las primeras emisoras "institucionales», se empezaron a impartir los cursos de locución diseñados por los técnicos franquistas en las Islas Canarias. Hasta entonces, las voces que salían al aire en las dos estaciones, privadas, instaladas en el archipiélago, Radio Club Tenerife EAJ-43 y Radio Las Palmas EAJ-50, eran tan diversas como las que se podían escuchar en las calles isleñas a los nativos y a los peninsulares residentes, caso de Victoriano Francés Suárez, el primer locutor en lanzar a los cuatro vientos el bando del general Franco contra la República. La norma la trajo, pues, la estación-escuela de la CAR montada a finales de 1955 en Santa Cruz bajo el indicativo Radio Juventud de Canarias, cuando el régimen, una vez había conseguido aliviar la miseria de la posguerra, extendió a las islas su preocupación por la formación profesional del personal radiofónico, incluyendo a los locutores, en su afán de imponer esa España «nacional» unitaria y sin fisuras en la que se había empeñado. En el caso que nos ocupa, sin embargo, lejos de reconocerse que detrás de la iniciativa se escondía el propósito de uniformizar el código verbal en el que se difundía la propaganda por todo el Estado, los técnicos justificaban tal imposición con el argumento de hacer de la señal emitida, con independencia del contenido de ésta, 
«arte» en el sentido formal del término. En consecuencia, las ondas hertzianas eran tratadas, por encima de su función comunicativa, como un cauce por el que se debía transmitir la belleza inherente a los sonidos $y$, en particular, los ricos matices de las voces humanas.

Probablemente, el miembro de la emisora que mejor ilustró tal concepción de la locución fue su último director, José Agustín Gómez García, un antiguo oficial de la marina mercante que, tras ingresar en el cuerpo de funcionarios del Frente de Juventudes, había fundado en 1951, y dirigido hasta su traslado a Canarias a inicios de los años setenta, Radio Juventud de Cartagena. Desde su puesto en la estación-escuela tinerfeña, el susodicho repetía, una y otra vez, a los jóvenes isleños que se matriculaban en sus cursos con la ilusión de ponerse algún día delante de un micrófono que, de la misma manera que el pintor hacía "arte» con los pinceles, los colores y el lienzo, ellos debían hacer lo propio con la voz, la música y los sonidos anejos que acompañaban el mensaje radiofónico. El principal requisito para alcanzar tales cotas estéticas era el uso del más puro castellano, lo que en las islas sólo se podía conseguir con un prolongado adiestramiento en la vocalización y la articulación de las consonantes porque en el habla isleña muchas de ellas se solapan entre sí o, simplemente, se omiten. Sin duda alguna, el escasísimo margen de maniobra que la dictadura toleraba para actuar sobre los contenidos de los mensajes por la censura y, ante la intimidación de ésta, la autocensura de los propios guionistas por temor, simplemente, a generar algún malentendido entre las autoridades franquistas, hace comprensible que los locutores isleños concentraran todos sus esfuerzos en esta vertiente específicamente formal porque, como dijimos, era la única en la que podían actuar sin riesgo a represalia alguna.

Sobre la concepción estético-formal de la locución radiofónica oficial, en la que se rebasaba ampliamente el objetivo de hacer de la palabra «el arte del bien decir» (Blanch \& Lázaro, 2012: 194), incidían dos factores previos que eran tributarios de la época. De un lado, la exigencia de unas voces bien timbradas y acordes a los roles sociales, el de cabeza de familia para el hombre y el de esposa-madre para la mujer, que la sociedad reservaba a ambos sexos. De otro, el tono serio y solemne que, salvo en los escasos espacios humorísticos, debía presidir el quehacer del locutor en todas las emisiones. Bajo tales premisas, Radio Juventud de Canarias diseñó, dentro de los llamados cursos de "radiofonismo", los específicos para los jóvenes isleños que aspiraban a ponerse delante del micrófono de una emisora. 


\section{Los cursos de locución}

Las primeras voces de la estación-escuela tinerfeña fueron seleccionadas por Adolfo González Amor, un militar peninsular de baja graduación que, con cierta experiencia en Radio Juventud de España en Madrid, asumió la responsabilidad de reclutar el elemento humano imprescindible para poder iniciar las emisiones. A tal fin, la emisora hizo un llamamiento a través de la prensa a los aspirantes a locutor, los cuales, tras la criba preliminar de los que no tenían el timbre de voz adecuado o carecían de los niveles mínimos de la dicción deseable, fueron adiestrados en la norma con unos ejercicios prácticos. Entre las primeras incorporaciones masculinas figuraron dos actores que, por su experiencia sobre el escenario, habían adquirido un alto nivel de competencia en la locución, uno peninsular, Manuel Escalera, y el otro tinerfeño, Ignacio García-Talavera, quien se haría luego cargo de los cursos; mientras que por el lado femenino entró una joven de 18 años recién llegada de Madrid, Mary Cruz Domínguez, que también estaba familiarizada con las artes escénicas porque era nieta del actor cinematográfico Luis Domínguez Luna. Meses más tarde, a mediados de septiembre de 1956, la estación-escuela organizó los primeros cursos para locutores y "actores, escritores, informadores, sonorizadores y sincronizadores», en los que se matricularon varias decenas de jóvenes. A los candidatos a ponerse delante del micrófono, además de tener los 18 años cumplidos y reunir los requisitos de "cultura general» y «buena conducta» típicos de la época, se les exigía "acreditar la posesión de estudios» en un conservatorio provincial de música y declamación como el que funcionaba en Santa Cruz, única manera de garantizar los niveles de vocalización y articulación deseables en un contexto como el isleño en el que el habla era tan diferente a la oficial.

A nuestras manos ha llegado mecanografiado en su versión original el contenido de uno de aquellos cursos de locución ${ }^{2}$ cuya relectura, haciendo un pequeño esfuerzo de imaginación para contextualizar su dinámica en la época, resulta sumamente ilustrativa para entrever, tanto las dificultades de su asimilación por los jóvenes isleños, como el enorme celo que se ponía en la forma al no poderse actuar en el contenido de los mensajes por la censura. Como preámbulo a los ejercicios prácticos, había un cuerpo teórico en el que se abordaban los rasgos básicos de la fonética española como si fueran los mismos en todo el Estado, hasta el extremo de incluir entre los errores el laísmo y el loísmo que están ausentes del habla isleña, las singularidades del lenguaje radiofónico y la tipología de los diversos textos que se podían leer ante el micrófono. Todo ello, como dijimos, sin hacer referencia alguna a la realidad insular porque, según se decía, «la radio no admite regionalismos, ni fonéticos ni sintácticos. No caben en ella modos de hablar, cabe tan solo el IDIOMA. EI

\footnotetext{
${ }^{2}$ El documento, reproducido en máquina de escribir con el típico papel calca de la época, lo conserva incompleto, en varios folios, el locutor fundacional de Radio Popular de Güímar, Ramón Negrín Fragoso, en su archivo personal.
} 
informador radiofónico no puede particularizar su lenguaje; al contrario, debe nacionalizarlo, utilizarlo en su más estricta pureza». $Y$, además de tener por norte el más puro castellano, con solemnidad, sin improvisaciones ni, mucho menos, confianzas con los oyentes porque, salvo en el terreno específico del humor, todo lo demás que se decía era «muy serio». Bajo tales premisas, los aspirantes a locutor tenían dieciocho listados de palabras agrupadas por sus afinidades fonológicas que debían leer "exageradamente despacio», en voz alta, de pie o sentados erguidos y, además, con reiteración hasta conseguir una articulación impecable de todas las consonantes. Valga como ejemplo el que a renglón seguido transcribimos:

Suscripción, adopción, expugnar, inexpugnable, admirable, adscrito, estructura, talud, eléctrico, exceso, es eso, es seso, es sexo, espectro, escéptico, fútbol, hectolitro, inepto, adicto, insignia, logaritmo, luminotecnia, lignito, obcecar, obsequiar, obstar, obtener, obstrucción, occipucio, descervigar, coxalgia, gozne, lezna, gazpacho, rapacidad, cisterna, cisma, sísmico, asistir, existir, desistir, coacción, ficción.

En paralelo a tales lecturas, se efectuaban unos ejercicios complementarios para hacer trabajar todos los músculos del aparato fonador, como leer en voz alta con un lápiz apretado contra la comisura de los labios para obstaculizar el movimiento de la lengua, y otros similares diseñados para mejorar de manera espontánea la articulación de las consonantes. Cuando la pronunciación en el más puro castellano de los dieciocho listados de vocablos alcanzaba los niveles de excelencia deseables, cosa nada fácil de conseguir porque éstos estaban escogidos por la dificultad de su pronunciación e intercalados con otros que diferían entre sí por matices que pasan inadvertidos en el habla isleña, se pasaba a la siguiente fase del curso, en la cual ya se leían pasajes literarios redactados con el mismo tipo de palabras. Antes de afrontar cada texto, los cursillistas tenían que hacer un estudio fonético, semántico y declamatorio del contenido, tras el cual procedían a su lectura silenciosa y, luego, en voz alta «las veces que sea necesario" porque a menudo, se decía, «nuestra voz interior» difiere de la que «nos va a salir luego» ante el micrófono. Para comprender las dificultades del ejercicio, basta con tener presente que todos ellos, estando plagados de términos en desuso, giros retóricos y usos totalmente ajenos al habla canaria, había que leerlos en el castellano más ortodoxo y "con sinceridad», esto es, con el énfasis y la entonación adecuados a su contenido. El texto que transcribimos a renglón seguido, habla por sí solo:

Vislumbro un majestuoso relámpago, cuya proyección hendió el plúmbeo cielo como una arista enrojecida y zigzagueante. El rayo agujereó la agreste montaña, que se estremeció en un zumbido espectral, enervante y estentóreo, de explosión volcánica, y los rimbombantes ecos rebotaron en una extensa área, por los valles y barrancos, cual si el orbe fuera a derrumbarse por inestabilidad. Los gélidos 
aquilones silbaron removiendo espeluznantes tolvaneras, que atizaron las helicoidales aspas de los molinos. Las nubes vertiginosamente se recogieron. Los pájaros, esquivando el turbión, se ovillaron acobardados, cobijados en las oquedades más abruptas, y la tempestad, en su apogeo turbulento, adquirió ambiente apocalíptico, hasta que el aluvión, en tromba, cayó sobre caminos y atajos, inundándolos. Anegó y devastó ubérrimos vergeles y sepultó en la aldea las débiles covachas de adobes. El mar embravecido, balanceaba una endeble corbeta de velas henchidas por el batiente torbellino, la cual fue a encallar en brusco envite o embestida, en un escollo, que horadó el estrado junto a la curvilínea y abollada quilla.

La educación de la voz también conllevaba el dominio del mayor número de registros posible, tanto humanos, desde los infantiles a los de la vejez, como animales, caso de los maullidos o los ladridos, a través de ejercicios orales repetitivos. Tantas eran las sesiones dedicadas a la reproducción oral de ruidos, sonidos, eslóganes y frases con entonaciones afectadas, que la imitación de las voces, incluyendo las del director de la emisora y el encargado de los cursillos, se convirtió en el principal motivo de las bromas que se gastaban los alumnos en los ratos libres. $Y$ para hacer confluir todas estas enseñanzas en una misma actividad estaba el teatro, tanto el radiofónico como, sobre todo, el representado en el escenario porque en éste, además de la declamación, se cultivaba la expresión corporal que también se consideraba fundamental para una buena locución. Paralelamente, para hacer perder el miedo a hablar en público, tan común entre los jóvenes de la época, y desarrollar la capacidad de improvisación ante cualquier imprevisto que pudiera surgir en un momento determinado, el propio Ignacio García-Talavera recorría en coche las calles de Santa Cruz con los cursillistas para que éstos explicaran, sin interrumpir la exposición, todo lo que se iban encontrando a su paso por la ciudad. Como colofón, los que superaban el curso debían permanecer un cierto tiempo en el estudio en calidad de "oyentes» para observar sobre el terreno cómo se desenvolvían los locutores que estaban en plantilla, al tiempo que empezaban a hacer sus primeros pinitos delante del micrófono con la lectura del indicativo de la emisora o de algún anuncio publicitario.

En los años setenta, cuando Ignacio García-Talavera había dejado la estación-escuela, las clases de "radiofonismo», que así se seguían titulando, estaban a cargo del nuevo director, recién llegado de Cartagena, José Agustín Gómez García. Por entonces, se trataba de unos cursillos de dos meses de duración impartidos en sesiones diarias de dos horas que, a pesar de las escasas posibilidades laborales que brindaban por entonces porque la radio estaba en una galopante crisis desde la irrupción de Televisión Española en Canarias en 1964, solía congregar a unos ocho o diez jóvenes atraídos por el medio. Lo que apenas había cambiado eran los objetivos y los métodos 
de aprendizaje, desde el control del aparato fonador con una finalidad estético-formal, hasta el desarrollo de la capacidad histriónica en el convencimiento de que para ser un buen locutor había que ser previamente un buen actor. Uno de los ejercicios más reiterados por José Agustín Gómez García consistía en que sus alumnos adoptaran, a una señal suya, actitudes de tristeza, alegría, incomodidad o ira; cuando no los invitaba a reír a carcajadas para, de golpe, hacerlos pasar al llanto. Para la mejora de la vocalización y la articulación de la pronunciación, el susodicho seguía echando mano de las viejas recetas de antaño en las que, además de la respiración, las pausas de los signos de puntuación y la dicción que demandaban los cánones de la época, se cuidaba muy mucho que la actitud corporal y gesticular guardara coherencia con los contenidos leídos.

En definitiva, aunque el contexto socioeconómico del tardofranquismo era bien distinto al de la autarquía por la apertura del país al exterior, el primer despertar de la pluralidad cultural del Estado y el crecimiento económico traído, a partir de los años sesenta, por el boom turístico, la locución radiofónica siguió anclada, al menos, en las Islas Canarias, en las mismas bases de siempre.

\section{Las emisoras ajenas a la capital provincial}

En el verano de 1960, con la simultánea puesta en marcha de La Voz del Valle de La Orotava, Radio Popular de Güímar y La Voz de la Isla de La Palma, la actividad pedagógica y asesora de la estación-escuela se intensificó para cubrir los nuevos puestos de trabajo creados en el sector. En el caso de la locución, los procesos de formación y selección fueron más complicados que los celebrados con anterioridad en Santa Cruz por las mayores deficiencias que, tanto en la vocalización como en la articulación del lenguaje hablado, había en las zonas rurales por el aislamiento y las escasas relaciones de sus habitantes con el exterior. En efecto, el hecho de que los pueblos e, incluso, los barrios fueran mundos encerrados en sí mismos, hacía que en todos ellos proliferaran dejes muy específicos, canarismos y vocablos no aceptados por la Real Academia que agigantaban las dificultades, de por sí enormes, con las que tropezaba el afán uniformador del régimen. Sobre tales premisas, los candidatos que mejor respondieron a los requerimientos de los técnicos fueron los jóvenes peninsulares que diferenciaban la pronunciación de las ces y las eses, los profesionales liberales con titulación universitaria, los estudiantes de los últimos cursos de bachillerato o primeros de diplomatura y los aficionados al teatro y al cante, estos últimos por la competencia adquirida espontáneamente en la dicción con ambas actividades; la inmensa mayoría de los cuales procedía de las clases medias. Los 
criterios de selección se centraron en captar a los que reunían las mejores condiciones innatas para la locución $y$, dentro de éstos, aquéllos cuyos timbres de voz se adecuaban a los roles sociales que el franquismo asignaba a los dos sexos.

El caso del personal de Radio Popular de Güímar, la pionera de las emisoras canarias en ingresar en la, todavía, embrionaria COPE, resulta sumamente ilustrativo. Los primeros locutores fueron reclutados entre los jóvenes del municipio que solían participar en las actividades teatrales de la delegación de Acción Católica y, paralela o alternativamente, tenían una sólida formación académica, caso del abogado, y futuro primer presidente del Parlamento de Canarias, Pedro Guerra Cabrera. Para cubrir las voces femeninas, en cambio, la dirección de la emisora puso sus ojos en el colegio religioso de la localidad, Santo Domingo de Guzmán, de donde fueron Ilamadas Isabel Medina y Marisol Fariña, dos bachilleres elementales que solían leer en voz alta, y en el más puro castellano, en todos los actos religiosos y festivos del centro; la primera de las cuales habría de convertirse en una de las autoras de literatura infantil más reconocidas en Canarias, y la segunda, a hacer de la radio su profesión de por vida en una época en la que la mujer estaba condenada a ser ama de casa al contraer matrimonio. Entre las restantes incorporaciones, no menos reveladoras fueron la de un joven asturiano recién Ilegado al municipio, Constantino Valdez Colunga, con experiencia en Radio Popular de Noreña, y el abogado, y futuro directivo del CD Tenerife, José Ramos González, artífice de un innovador programa deportivo que, a la sazón, fue el de mayor audiencia de la isla en la primera mitad de los años sesenta entre los de producción isleña.

En años sucesivos, con el asesoramiento de la estación-escuela de Santa Cruz, la emisora organizó varios cursillos de reciclaje y abrió nuevos procesos de selección para cubrir las vacantes que se fueron produciendo en la locución y los puestos técnicos. Entre el personal propio dedicado a tales menesteres, figuraron un maestro nacional vasco destinado por entonces en la isla, Javier Apraiz de Elorza, y un alumno grancanario de canto del conservatorio provincial de música y declamación, el futuro tenor Suso Mariátegui, los cuales habrían de destacar sobremanera en sus respectivas profesiones, ambas ajenas a la radio, después del franquismo. El primero, que luego se doctoró por la Universidad de Salamanca en el campo de la educación especial y llegó a asumir la responsabilidad del área en el gobierno autonómico del País Vasco, puso especial énfasis en las diferentes entonaciones que debían darse a las lecturas de las esquelas, anuncios, dedicatorias de discos y, en definitiva, a los textos en función de sus funciones y contenidos. El segundo, que habría de completar su formación vocal en Viena, actuar en los escenarios de ópera más prestigiosos del mundo, grabar varios discos e impartir clases en la Escuela Superior de Música Reina Sofía de Madrid, introdujo una cierta especialización entre los locutores con la asignación preferencial de los registros disponibles a los distintos mensajes radiofónicos. Los perfiles expuestos, por lo demás, sintetizan otra de las características del colectivo humano 
que en los años de franquismo colaboró en las emisoras canarias, las ansias de superación personal y las inquietudes culturales ajenas, cuando no antitéticas, a las tesis ideológicas de la dictadura.

En lo que respecta a las dos emisoras sindicales, La Voz del Valle de La Orotava y La Voz de la Isla de La Palma, la estación-escuela de Santa Cruz organizó, nada más anunciar el Sindicato Vertical su intención de instalarlas, sendos cursillos de formación al que asistieron varios jóvenes de ambas localidades. La parte de la locución corrió a cargo de Ignacio García-Talavera que, por entonces, había ingresado como profesor en el conservatorio de música y declamación de la provincia, tras someter a los aspirantes a una criba a través de algunas lecturas en las que seleccionó a los que tenían las mejoras cualidades innatas en el color de la voz y la dicción. Concluidos los cursillos, la documentación pertinente fue remitida a los encargados de la programación de ambas emisoras, el sacerdote José Siverio en La Voz del Valle que, a la sazón, era uno de los pocos titulados en la Escuela Oficial de Periodismo de Madrid que, por entonces, había en Canarias, y el joven licenciado en Ciencias Químicas, y futuro Diputado del Común (el equivalente isleño al Defensor del Pueblo), Luis Cobiella Cuevas en La Voz de la Isla de La Palma. Al igual que sucediera con el grueso del personal atraído por la radio en la época, tanto uno como otro se distinguiría con el paso del tiempo por sus inquietudes culturales ajenas a la política y, en particular, por la música, el primero como director de corales y el segundo como compositor de piezas musicales, y poemas, para las fiestas lustrales de La Palma. Porque en ambas emisoras, los militantes del régimen se reducían a los delegados sindicales de una y otra comarcas que, en teoría, eran los respectivos directores, $\mathrm{y}$ al personal administrativo que, asimismo, era designado por el Sindicato Vertical.

Los procesos de selección se mantuvieron abiertos en todas las emisoras a través de actividades teóricas y prácticas para los jóvenes bajo el asesoramiento de la estaciónescuela, con los que se cubrieron las necesidades derivadas de la progresiva ampliación de los horarios de emisión y las bajas causadas en el personal contratado. Aunque las dificultades para reclutar las voces ortodoxas eran mayores en las zonas rurales, no es menos cierto que tales inconvenientes estaban paliados por la relajación de los controles de la dictadura en los espacios marginales y periféricos del Estado. En consecuencia, éstas fueron las señales por las que más salieron al aire las formas de hablar que podían escucharse en la calle, lo que en los años centrales del franquismo representaba, en contraposición a los de la transición democrática, un indicador de irrelevancia que guardaba coherencia con los bajos índices de audiencia por la reducida cobertura geográfica de todas ellas. La infravaloración del habla canaria era un componente más de la baja autoestima que tenía la población insular en un contexto en el que todo lo relacionado con la cultura autóctona se consideraba de categoría inferior, como también sucedía en Andalucía, Galicia y las restantes demarcaciones territoriales del Estado, a tono con el subdesarrollo del país. Sin duda 
alguna, la costumbre de muchos de los isleños que iban a la península de regresar pronunciando, como signo de diferenciación y distinción ante sus paisanos, las ces, era la manifestación más grotesca de aquella realidad que, como dijimos, invertirá sus posiciones tras el franquismo, cuando el habla autóctona pasó a la vanguardia y dejó a la castellana como expresión de la tradición franquista.

\section{La reacción de la sociedad insular}

La obsesión creada con la norma, quedó magníficamente reflejada en el artículo que el rotativo El Día de Santa Cruz de Tenerife publicó el 14 de febrero de 1968, en la página 8 , de Fernando Delgado, el alumno más aventajado de los cursos de locución de la estación-escuela, quien aún conserva la impecable articulación aprendida de todas las consonantes, incluidas la c y la z. En efecto, el que habría de dirigir Radio Nacional de España, presentar los telediarios de fin de semana de Televisión Española, conducir el magacín A vivir que son dos días de la SER, colaborar en El País y el grupo Prensa Ibérica y, por si fueran pocos los méritos, ganar el Premio Planeta con su novela La mirada del otro, se quejaba por entonces del "maltrato» que recibía "la lengua española en la radio», lo que sólo se puede entender a la luz de los resquicios de la programación de producción propia por los que, conforme avanzaron los años sesenta, se coló cada vez más el habla popular. Nos referimos, de un lado, al desarrollo de la programación deportiva al calor de las mejoras socioeconómicas de la época y, en particular, a las corresponsalías en los pueblos de los jóvenes aficionados que, evidentemente, hablaban de manera espontánea a través del teléfono; y de otro, a los espacios que, conforme se acentuó la crisis del sector por la irrupción de la televisión, quedaron en manos de los colaboradores que, asimismo, no habían recibido curso de locución alguno. Porque hasta entonces, la presencia del habla isleña se había reducido a los espacios culturales que, en el sentido más eximio del término, estuvieron en antena hasta bien avanzada la década de los sesenta a cargo de la minoría artística e intelectual isleña, en los que la dicción de los conferenciantes y recitadores nada tenía que ver con la de los cronistas de los partidos de fútbol locales, por más que unos y otros hablantes no diferenciaran las ces de las eses y compartieran determinados giros.

Las proporciones correspondientes a ambas locuciones, la académica y la isleña, siempre fueron muy desiguales de unas emisoras a otras, en función del emplazamiento, urbano o rural, de cada una de ellas, y del contenido de los diferentes programas, dentro del uso compartido de la norma en los espacios de producción propia más importantes y, evidentemente, las conexiones con la península. Los males que denunciaba Fernando Delgado a inicios de 1968 están ilustrados, 
paradójicamente, con la labor de un colega suyo que, asimismo, habría de destacar sobremanera en los medios estatales después del franquismo. Nos referimos a Juan Cruz Ruiz que, cuando era todavía un adolescente, empezó a colaborar con crónicas deportivas y trabajos literarios en La Voz del Valle de La Orotava sin haber realizado, como tantos otros compañeros de afición, curso previo alguno de adiestramiento vocal. Es más, el que habría de contarse entre los redactores fundadores del diario El País, asumir la dirección de la editorial Alfaguara, escribir una veintena de libros entre novelas y ensayos y participar como contertulio en tantos programas relevantes de radio y televisión, no sólo infringía la ortodoxia a la hora de pronunciar las consonantes sino que, además, tenía un timbre de voz atiplado, como es de sobra conocido, que no casaba con los cánones de la época. Pero, como dijimos, tales usos sólo se toleraban en los espacios dirigidos a segmentos muy concretos, y poco exigentes, de la audiencia, dado que los tramos más relevantes de la programación salían al aire en el código oficial de la radiodifusión franquista.

La respuesta de la sociedad insular ante tal imposición se encauzó, mientras duró la dictadura, por la única vía posible, la del humor, a través de la creación de una serie de personajes de ficción que, llevando a los extremos más grotescos el habla campesina isleña, tuvieron una enorme aceptación entre el público. El espacio pionero del género apareció en Radio Club Tenerife a finales de los años cuarenta, cuando Pepita Varela, Arturo Navarro Grau y Plácido Bazo pusieron voz a las peroratas de "Seña Pepa, Cho Juan y Cho Venancio», cuyos guiones escribía el segundo. El éxito fue tan grande que hasta la estación-escuela, la encargada de formar académicamente a los locutores, siguió el ejemplo con "los monólogos de Cho Juan, el alcalde de las Mercedes», éstos a cargo del funcionario del Cabildo Santiago Puertas; así como el Centro Emisor del Atlántico de Radio Nacional de España, donde se hicieron célebres "las voladas de Seña María» de la maestra nacional Luisa Machado. Sin duda alguna, el acierto de la fórmula derivó del enorme contraste que había entre la calmosa y heterodoxa dicción isleña frente a la ágil, solemne y exquisitamente articulada que se consideraba como propia de la radio, lo que creó el clima adecuado para, por la vía de la antítesis, convertir a los alegatos parsimoniosos, ingenuos y plagados de canarismos $y$ vulgarismos de los campesinos en tema de humor. Para confirmar que se trató de un producto radiofónico tributario del contexto, basta con comprobar su paulatino cese, hasta desaparecer, conforme el habla autóctona se adueñó del medio, en un proceso gradual cuyos últimos coletazos quedaron testimoniados en el libro que, en 1987, publicó el antiguo locutor de Radio Popular de Güímar y, por entonces, presidente del Parlamento de Canarias, Pedro Guerra Cabrera, bajo el elocuente título El habla canariense y los políticos. iJablen ansina, cristianos!

A partir de los años de la transición democrática, la consabida ley del péndulo se ha encargado de imprimir una atracción tan fuerte a la locución popular en Canarias que, ante los efectos perniciosos de sus versiones más radicales, se ha generado un debate 
a partir de un cúmulo de argumentos que van desde la reivindicación de los valores identitarios propios a la defensa de la claridad y la corrección que deben presidir la emisión de todo mensaje radiofónico. Lejos de constituir un caso específicamente isleño, se trata de un fenómeno generalizable a todas las demarcaciones territoriales del Estado cuyas hablas diferían de la ortodoxa, al igual que sucediera en la Italia de la posguerra con la modalidad impuesta por el sector estatal de la radiodifusión, la RAI, cuando irrumpieron las emisoras independientes y, con ellas, afloró la diversidad lingüística del país trasalpino en las ondas hertzianas (Eco, 1981: 213-216). Pero con el paso de los años, la polémica ha dejado claro que no se trata de dos opciones excluyentes entre sí, sino, más bien, de los dos polos extremos de un todo continuo en cuyo tramo central se considera que los «acentos oriundos utilizados con naturalidad y adecuada vocalización, embellecen y globalizan la información» (Ávila, 2000: 19). Todo ello, en coherencia con el actual Estado de las Autonomías en el que todos los mecanismos de la vida social, lejos de estar encauzados por una ortodoxia intransigente como la franquista, están abiertos a la pluralidad inherente a toda sociedad democrática y a la "aldea global» en la que, cada vez más, está inmersa la humanidad, donde el relativismo y la tolerancia no han hecho más que ganar terreno al calor de las corrientes intelectuales posmodernas.

En la actualidad, los cursos de locución se siguen recomendando e impartiendo en España, aunque no para imponer un habla determinada sino para, respetando la heterogeneidad de los hablantes, dotar a la voz del profesional, «una vez amaestrada,... (del)... mayor número de matices sonoros para aplicarlos cuando la ocasión lo demande» sabiendo, además, «relajar, tonificar, rasgar, forzar, subir y bajar la voz sin dañarse las cuerdas vocales» (Ávila, 2000: 11). En consecuencia, aunque los trabalenguas y muchos de los ejercicios prácticos de antaño conservan su vigencia o, simplemente, han sido actualizados, los objetivos ahora son totalmente opuestos a los franquistas, tanto como lo es el contexto español desde la incorporación al mundo occidental, la descentralización del Estado, la globalización y, como un acicate más para la pluralidad, la incidencia del pensamiento posmoderno. Sobre tales bases, y el hecho de que ahora prevalezca lo que se dice sobre cómo se dice, resulta comprensible que las Islas Canarias aporten a los medios audiovisuales estatales voces tan antitéticas como las ya citadas, cuando en la dictadura tenían rangos tan desiguales, del locutor Fernando Delgado y el tertuliano Juan Cruz Ruiz. En efecto, mientras el primero posee un excelente color de voz y articula las consonantes como si hubiera nacido en el corazón de Castilla, aunque con la particularidad de hacerlo con la suave cadencia isleña, el segundo, que carece de las más mínimas cualidades vocales, se expresa, para mayor contraste con su paisano, en su habla natal en los estudios de radio y los platós de televisión. Ello no contradice el hecho de que la claridad en la transmisión del mensaje ocupe un lugar central en la formación del locutor incluyendo, evidentemente, todo lo relativo a la locución. Es más, como «vivimos en una sociedad democrática en la que sólo un arma debe ser admitida: la palabra» (Blanch \& Lázaro, 
2012: 193), suscribimos con estas dos autoras que, dentro de la pluralidad inherente al actual «hibridismo cultural» (Burke, 2010: 63-72), tal objetivo es en buena medida extrapolable a los planes de estudios de todas las ramas del saber.

\section{Conclusiones}

Durante la dictadura franquista, el empeño del régimen en uniformizar, bajo unos determinados valores que justificaba con el adjetivo de "nacionales», a todo el territorio estatal, no sólo incidió en los contenidos de las emisoras del país sino, además, en el código en el que éstos se emitían, el más puro castellano, lo que iba contracorriente en un contexto cultural tan diverso como el de España. En el archipiélago canario, donde el habla disentía, y disiente, sobremanera de las peninsulares en su conjunto, la norma se implantó a través de los cursillos de locución de la estación-escuela de la Cadena Azul de Radiodifusión (CAR) montada en Santa Cruz de Tenerife a mediados de los años cincuenta, donde los jóvenes isleños aspirantes a locutor fueron adiestrados vocalmente para dirigir a sus paisanos un mensaje visado por la censura bajo unas formas totalmente ajenas a los usos cotidianos de éstos. La reacción de la sociedad insular se articuló, en un principio, a través del resquicio del humor que supuso escuchar en la solemne radio de la época las peroratas desenfadadas de los campesinos canarios $y$, desde que empezó a resquebrajarse el andamiaje de la dictadura, con el asalto de las versiones más radicales del habla propia a los micrófonos de las emisoras. Por consiguiente, hasta en la vertiente lingüística la presión uniformadora franquista consiguió el efecto contrario al deseado y, en consecuencia, dio alas al movimiento reivindicativo que, en favor de las señas de identidad regionales, puso en jaque las tesis del régimen en todo el Estado desde finales de los años sesenta.

El hecho de estar centrada la investigación en un espacio geográfico muy concreto de España, las Islas Canarias, no ha sido óbice para que sus resultados arrojen abundante luz sobre el debate que, a partir de la transición democrática, ha suscitado la locución radiofónica en su doble condición de reflejo del acervo cultural propio y de código de comunicación al servicio de la sociedad. Además, sin haber reducido el objeto de estudio a un microespacio tan aprehensible y diferenciado como el isleño, no hubiéramos sido capaces de recopilar un cuerpo de datos lo suficientemente representativo de la realidad referenciada como para poder abordar, con el rigor deseable, un tema tan «vaporoso» como el de las secuelas de las políticas lingüísticas del franquismo en la locución radiofónica. Y aunque el contexto se pueda catalogar como "local», tampoco podemos pasar por alto que estamos ante un archipiélago atlántico cuyo hecho diferencial es tan acusado que, desde las perspectivas científicas, 
no es aconsejable subsumirlo en el conjunto del Estado a la hora de abordar temas tan poco trabajados como el presente.

\section{Referencias bibliográficas}

AguAdo MONJAS, G. (1992): La Televisión Pública en Canarias, tesis doctoral inédita, Departamento de Periodismo IV de la Facultad de Ciencias de la Información de la Universidad Complutense, Madrid.

ÁVILA, A. (2000): Manual práctico para iniciarse como locutor de radio. Reglas, normas y técnicas de gran utilidad para ser locutor de radio, Editorial CIMS 97, Barcelona.

BALSEBRE, A. (1994): La credibilidad de la radio informativa, Feed-Back, Barcelona.

- (2002): Historia de la radio en España (1939-1985), vol. II, Ediciones Cátedra, Madrid.

BLANCH, M. \& P. LÁZARO (2012): Aula de locución, Ediciones Cátedra, Madrid.

BLANCO, I. \& P. FERNÁNDEZ (coords.) (2004): El lenguaje radiofónico: la comunicación oral, Fragua, Madrid.

BREISACH, E. (2009): Sobre el futuro de la Historia. El desafío posmodernista y sus consecuencias, Universitat de València.

BURKE, P. (1999): La Revolución Historiográfica Francesa. La Escuela de los Annales: 1929-1989, Gedisa Editorial, Barcelona, 3a edición.

- (2010): Hibridismo cultural, Akal, Madrid.

BUSTOS SÁNCHEZ, I. (coord.) (2007): La voz: la técnica y la expresión, Paidotribo, Barcelona, 2a edición ampliada y revisada.

CEBRIÁN HERREROS, M. (1994): Información radiofónica, Síntesis, Madrid.

CHECA GODOY, A. (2009): "Prensa y radio en Sevilla del tardofranquismo (19511975)», en Langa Nuño, C., Romero Domínguez, L.R y Ruiz Acosta, M.J. (coords.), Un siglo de información en Sevilla (prensa, radio y televisión): 1909-2009, Universidad de Sevilla, pp. 165-206.

DÍAZ ALAYÓN, C, MORERA, M. \& ORTEGA, G. (2003): Estudios sobre el español de Canarias: actas del I Congreso Internacional sobre el español de Canarias, Academia Canaria de la Lengua, La Laguna (Tenerife), Islas Canarias. 
DÍAZ SÁNCHEZ, L. (1997): La radio en España, 1923-1993, Alianza Editorial, Madrid.

ECO, H. (1981): «Una nueva era en la libertad de expresión», en Lluís Bassets (ed.), De las ondas rojas a las radio libres, Editorial Gustavo Gili, Barcelona, pp. 213-236.

FAUS BELAU, J. (2007): La radio en España (1896-1977). Una historia documental, Taurus/Santillana, Madrid.

FERNÁNDEZ AREAL, M. (1973): El control de la Prensa en España, Guadiana de Publicaciones, Madrid.

FRANQUET, R. (1994): Ràdio Barcelona. 70 anys d'història, 1924-1994, Diputació de Barcelona y Collegi de Periodistas de Catalunya, Barcelona.

GARITAONAINDÍA, C. (1988): La radio en España, 1923-1939. De altavoz musical a arma de propaganda, Siglo XXI y Universidad del País Vasco, Bilbao.

GONZÁLEZ CONDE, M.J. (2001): Comunicación radiofónica, Universitas, Madrid.

GUTIÉRREZ, M. \& J.J. PERONA (2002): Teoría y técnica del lenguaje radiofónico, Bosch Comunicación, Barcelona.

HAYE, R. (2004): El arte radiofónico, La Crujía, Buenos Aires.

HUERTAS, A. \& J.J. PERONA (1999): Redacción y locución en medios audiovisuales: la radio, Bosch Comunicación, Barcelona.

IGGERS, G.G. (1998): La ciencia histórica en el siglo XX, Idea Universitaria, Barcelona.

MENDIETA, S. (1993): Manual de estilo de TVE, Labor, Barcelona.

MURELAGA IBARRA, J. (2009): "Historia contextualizada de la radio española del franquismo (1940-1960)», en Historia y comunicación social, Departamento de Historia de la Comunicación Social, no 14, Facultad de Ciencias de la Información de la Universidad Complutense de Madrid, Madrid, pp. 367-386.

RODERO, E. (2003): Locución radiofónica, IORTV, Madrid.

RODRÍGUEZ, J.M. (1999): Técnicas de locución radiofónica, IORTV, Madrid.

SINOVA, J. (1989): La censura de Prensa durante el franquismo (1936-1951), EspasaCalpe, Madrid, 2ª edición.

YANES MESA, J.A. (2007): Los orígenes de la COPE en Canarias. "Radio Popular de Güímar», 1960-1969, Ediciones Baile del Sol, Tegueste (Tenerife). 
- (2009): Las ondas juveniles del franquismo. "Radio Juventud de Canarias", 1955-1978, Ediciones Baile del Sol y Dirección General del Libro, Archivos y Bibliotecas del Gobierno de Canarias, Tegueste (Tenerife).

- (2011): «La propaganda radiofònica de l'Espanya nacional a Canàries durant la Guerra Civil, 1936-1939», en Anàlisi. Quaderns de comunicació i cultura, Departament de Periodisme de la Comunicació, no 41, Universitat Autònoma, Barcelona, febrer 2011, pp. 101-116.

- (2012): La radiodifusión privada en España durante el franquismo. Radio Club Tenerife, 1939-1975, Ediciones Densura, Güímar (Tenerife).

- \& RODRIGO F. RODRÍGUEZ (2007): La radiodifusión sindical del franquismo. "La Voz del Valle» en las Islas Canarias, 1960-1965, Ayuntamiento de La Orotava, Cabildo de Tenerife y Dirección General del Libro, Archivos y Bibliotecas del Gobierno de Canarias, La Orotava (Tenerife).

- \& EDMUNDO HERNÁNDEZ CABRERA (2011): "La Voz de la Isla de La Palma», 1960-1978. La radiodifusión del sistema comunicativo más singular de Canarias en el franquismo, Ediciones Alternativas, Puntagorda (La Palma). 